\title{
The temporary use as a strategy for transforming the space of contemporary cities. Space transformations supported by the purposeful application of temporary use, based on a case study
}

\begin{abstract}
Temporary use as a subject of work should be understood as temporary development or use of land and facilities, in a way that allows the best use of spatial resources at a given time and place. The author takes up the topic of temporary use being an intentional element of strategy in the design and planning of space. Analysis of practical applications focuses on the depiction of models of design and planning processes, the element of which is the temporary use of space and overall transformation processes, as well as features and functions of temporary uses. The researched practices concern processes composed of various elements, eg mutual relations of temporary use with permanent development. The analysis of good practices indicates a significant strengthening of the potential for temporary use, if it is implemented through a network of broad connections and the integration of various activities and environments.
\end{abstract}

Keywords

Temporary uses • tactical urbanism • pop-up city • urban renewal • city planning

(C) University of Warsaw - Faculty of Geography and Regional Studies

\author{
Karolina Marta Szaton \\ Department of Urban and Spatial Planning, \\ Faculty of Architecture, Silesian University of \\ Technology, Gliwice, Poland \\ e-mail: karolinaszaton9@gmail.com \\ Received: 5 March 2018 \\ Accepted: 16 September 2018
}

\section{Introduction}

It seems that our culture is attached to stability, which we associate with security, power, and control. It therefore happens that we perceive temporariness as something provisional, something of dubious quality, a substitute activity, or just a temporary lack of ideas. On the other hand, temporariness is very up-to-date. For the sociologist, Zygmunt Bauman, the word "fluidity" (Bauman 2000), which is associated with variability and also temporariness, is the key word that describes the present day. The dynamic lifestyle within cities increasingly redefines the concept of time in the context of space. Time becomes the fourth dimension of design, and the many good solutions that have been implemented show that temporariness in space management opens up new possibilities; this can be activation, stimulation, impulse, or experimentation. As Peter Bishop and Lesley Williams point out: " ... in such a world temporary activities of all kinds could be expected to flourish" (Bishop \& Williams 2012).

The subject of research and its state

In order to investigate the concept of temporary use in the context of this paper, it seems necessary to define the meaning of temporary use on which the selection of "good solutions" are based, which are, in turn, the basis for the described research. Temporary use is not an unequivocal term, especially with reference to the legal acts of individual countries. Temporary use, which is the subject of this article, should be understood as the temporary use of land, or the development of land or facilities in a way that allows the use of spatial resources in a given place and time, or as a response to the current needs of users. The temporary use of space as defined above is used as a tool or element of urban transformation strategies - a tool that can be of particular interest to urban planners, planners, or society, as well as entrepreneurs who are willing to influence the image of space in the form of spatial planning, economic change, or social and image transformation. The key to case studies are therefore,

- the sense of using temporary land development to achieve a desired effect in a given space;

- the presentation of the topic of temporary use in the context of processes - changes, transformations, development of a given area;

- the presentation of the topic of temporary use directly as a part of the design or planning process;

- the connections and relations between elements of temporary use and other elements of the processes mentioned above including permanent development - in the context of the time horizon of events, elements of participation, financing, and the activities of individual stakeholders.

In scientific studies, temporariness has been considered in various contexts and at various scales. The concept of tactical urbanism also appears in studies and anticipates, among other things, the use of temporariness in dynamic and flexible space management. Research on small grassroots initiatives, called grassroots urbanism or handmade urbanism, is also developing (eds Rosa, Weiland 2013), as it is on pop-up cities (Beekmans, de Boer 2014), which is the short-term use of places in the city. Existing studies cover a wide range of case studies, but rarely go beyond mere observations of the existing state of the subject. There have been attempts to create a typology of the phenomenon of 
temporariness in urban planning (Oswalt et al. 2013) and to carry out research on its causes and the conditions favorable for its formation (Bishop \& Williams 2012). The connections and relationships between the spatial planning system and temporary use are also being examined; and in a few places there are attempts at real action that make use of such cooperation and tools to enable the use of space, objects, and places, in a temporary manner; for example, the DC Temporary Urbanism Program: Washington; and Temporary Use as a Tool for Urban Regeneration: Rome, Bremen, Alba lulia.

In Scotland, temporary use even found application in the government's Stalled Spaces Scotland program run by Architecture and Design Scotland. The program was created to "encourage and support communities to bring stalled spaces or derelict and vacant land back into temporary use."1 In Poland, temporary spatial management, as a research subject, is eagerly considered in the context of the development and management of urban abandoned and uncultivated areas; that is, spaces in cities that are in the process of transformation or have suspended their previous function. This issue is raised, for example, by Weronika Wiśniewska (Wiśniewska 2012). Temporary use also fits into modern ideas such as "design thinking" - an idea which is close to prototyping. Prototyping in design thinking is the basis for designs tailored to the needs of users. The topic is therefore important for the development of the so-called "creative class," and allows it to try out new ideas. This class plays an important role in the economic development of the city (Florida 2010). The subject also finds application in architecture, in the realizations of well-known offices such as the project by the Dutch MVRDV studio presented at the Dutch Design Week 2017 festival, which was a hotel with rooms that could be converted.

The literature thus shows great potential for temporary use, both as grassroots activities and top-down activities. In addition to the analysis in scientific research of existing effective implementations, a synthesis, and an answer to the question on how to get good results from utilizing temporary use as a tool in diverse, often complex conditions, are still needed. Therefore, it is critical to deepen the research on methods and methodologies, and to continue looking for model actions in the context of the overall transformation process.

\section{Aim and methods of research}

It is not always possible to predict which spatial solutions temporary use will lead to, but it is possible to plan the process and define the goals, form, and function that it adopts during the design and planning process. The path of individual activities may, however, be dependent on, and matched with, results that have been gradually obtained, depending on other co-occurring elements within the planned transformation process. The aim is to build a model of activities and strategies for such processes, and to show their multidimensionality, network connections, and the broad context of co-existing elements. In the world of projects that are classified by Rem Koolhaas under the category of projects L and XL (OMA, Koolhaas \& Mau 1995), and considered to be indicators of prosperity and modernity; we are accustomed to accepting stable, new developments as a positive indicator of the results of activities in spaces. Meanwhile, "Cities need big plans but also small tactics," (Lydon \& Garcia 2015) according to Mike Lydon and Anthony Garcia. In the case of using temporary use as a tool for urban transformation, the aim is to emphasize the role of process planning and the design of the elements of the process, which should not always result in permanent development. It's easy to simplify the understanding of temporary use and limit its praxis only to the use of perishable materials and

${ }^{1}$ Architecture \& Design Scotland 2018. gatherings of people - to municipal theater for those who seek activity in modern cities.

This paper's research is based on good practice, whose positive results in the form of permanent changes in urban space are confirmed by the literature. The source of the data is, in particular, the literature describing selected examples of temporary use, extended by my own studies of the areas covered by the analysis, and in the context of the conditions, problems and events in the space that occurred before the described temporary use.

The examples are also supplemented with the latest events and transformations, which are not described in the available literature but are necessary to fully illustrate the transformations. They have been extended to include up-to-date information from websites, local press, statements and design manifestos dealing with individual projects, relations of users with the examined space, and our own observations.

\section{Research - case study}

The following examples illustrate the utilization of temporary use as a tool for transformation in three different cases. They were selected to represent a variety of project scales; each responding to their own problems, with each case locating temporary use elsewhere in the transformation process or planning process. The three examples are outlined below.

- Putnam Triangle Plaza is an example that represents temporary use as an element of the design process that was entirely planned and implemented according to a schedule. Temporary use co-exists here with other elements of the process.

- 100 Union Street is a series of regular projects, but each of the projects has been planned individually and the main intention was to utilize only temporary use - no other tools have been used in the transformation process. The individual stages of the process were the product of the positive results of successive undertakings that did not have a specific time-frame of use. The key, in the context of this case, has been the design process for individual, successive implementations, as well as their mutual relations.

- The last of the examples - Westergasfabriek, the former municipal gas plant in Amsterdam - is a model that shows a large scale project in which temporary use also finds application as an intentional transformation tool. It coexists and combines with other elements of the renewal process, however, it plays a major role in giving direction to the development of the area.

\section{Putnam Triangle Plaza, New York}

The Putnam Triangle Plaza project is part of the NYC Plaza Program, which is based on the transformation and renovation of unused or forgotten, poorly functioning, public spaces in the city. The goal of the program is to locate and make public spaces available so that at least one such space is accessible within a ten-minute walk of another. One of the activities supported by the program was the transformation of the square at the intersection of Putnam Avenue, Grand Avenue, and Fulton Street, which was initiated by Fulton Area Businesses and the Municipal Transport Department. The main goal of the project was to restore public space to pedestrians. The idea of making the space available was to connect the square with the pedestrian area next to the existing buildings, which was, at the time, separated by a road. In addition, the location was for a long time associated with crime and drugs, as well as being the location of many accidents. A number of activities were, therefore carried out between 2011 and 2017, which was preceded by the planning of the vision of the transformation process. 
The activities were aimed not only at the new development of the space, but also at creating deep structural changes in social terms. The initiators took on the task of building a truly living public space that could be given the name "place;" a space defined in a given place and time, and with a new identity. One of the important elements of the process of changing this space was in utilizing temporary use in the broad context of other related activities. The first stage of the transformation process consisted of conducting workshops with potential stakeholders that were aimed at initiating discussions about the area's problems, and clearly linking the project to the intention of changing society's perception of the place. Expectations regarding the elements of the square's development, as well as a program of events that was to become an inseparable element of the overall transformation process, were also determined. The events' organization was based on a local network of connections and the inclusion of partners, especially local entrepreneurs, in the process. At this stage, the project anticipated only the use of temporary elements of development, while a street fragment separating the square was also closed, but without introducing infrastructural changes. The next stage, which was implemented three years into the project, was another workshop, the aim of which was to verify the solutions that had been applied. A number of statistical surveys were also carried out to illustrate the scale of the changes in the context of the previous problems, in particular the area's security. After analyzing the results, the development was updated; a new project was created that was based on current social needs, while a new project of events also came into being. The last element of the project, implemented after subsequent consultations at the turn of 2016 and 2017, was a permanent development based on an infrastructure project. Temporary use, therefore, played a key role in the context of the process. It provided the opportunity for the space to be activated without taking uncertain and expensive infrastructure measures at the beginning of the planned transformation. The flexibility of such an operation allowed for the development of a project that responded to the needs of specific users. However, the key to the project was not only the new development of the space, but essentially a change in society's perception of the area and the minimization of pathological behaviors. The coordination of activities that combined elements of participation, temporary use, and permanent development, provided the possibility for controlled changes to the place. The model for the entire process is shown in figure $1 .{ }^{2}$

\section{Union Street, London}

Union Street belongs to a part of the city that, for a long time, couldn't get rid of its bad reputation; this impinged on the investments that were planned for the area, and created unfavorable attitudes in potential new residents. In the Union Street area, therefore, the stereotype of being "on the wrong side of the river" could be felt, and it became a reason for considering how to redefine this space. Giving a new meaning and economic future to the area was the basis for activities that were implemented on a "temporary" free plot. The first project implemented in this area, which initiated the transformation process in 2008, was the EXYZT collective's project known as the Lido (a temporary [seasonal] swimming pool), which was implemented on a relatively small undeveloped private plot as part of the London Architecture Festival. The project consisted not only of the implementation of an interesting spatial design, but also of the organization of a schedule full of events that took place during the action. The entire implementation was based

${ }^{2}$ The case study was based on information available on various websites, including: Fulton Area Businesses 2018 (https://faballiance.org/) and the report: NYC, Putnam Triangle Plaza, Brooklyn CB2 Transportation Committee, March, 2015.

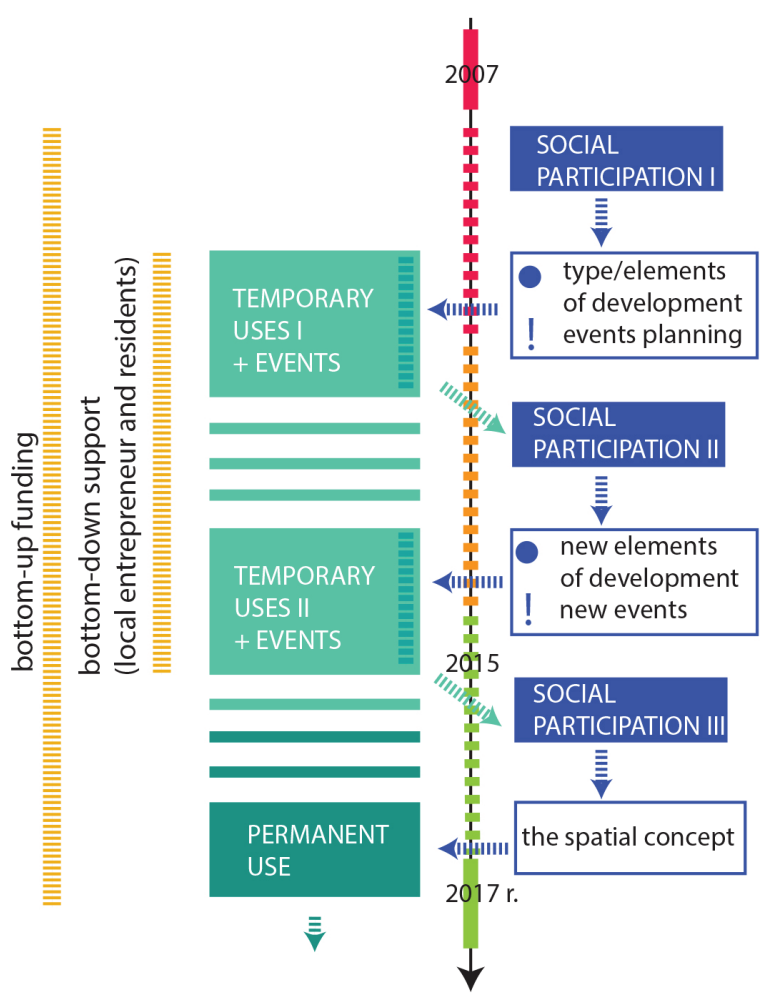

Figure 1: This model shows the elements for the entire renewal process for Putnam Triangle Plaza in New York.

Source: The scheme for purposes of the publication made by Karolina Szaton.

on a network brought together by the designers, consolidated in the joint process of construction and active use of space, and linking the local community, local entrepreneurs, support for the plot owner, and recommendations for culture and science centers. The implementation turned out to be an extremely successful project that initiated a several-year process of spatial actions and events in this area. Another project, initiated this time by Wayward and its manager, Heather Ring, was the Union Street Urban Orchard, a temporary public orchard. It was created as an element of another process - one of the actions of the strategy for land renewal (Bankside Urban Forest Strategy) in 2010. One year later, Wayward returned with a flagship project called the Union Physic Garden - a garden, this time, modelled on a hospital or pharmacy - whose main theme was the promotion of a healthy lifestyle and food, especially herbs used as curatives. In 2012, the EXYZT collective returned again to Union Street with the ReUnion project, which was a public place to hang out - a pub, a neighborhood house, a place for meetings and discussions. It was a public space available to everyone in the city center. In the summer of 2013 yet another project was created - "The Lake" - also realized by the collective. This time, among the buildings, directly next to the pavement, and separated only by a fence in the shape of drawbridges set next to each other; an artificial lake was created.

Between the years 2014 and 2016 the last project for temporary development of the plot on Union Street - "The Union Yard" - was completed. This lesser known project was created by several EXYZT members and built with the support of a permanent group of residents involved in previous projects. This "local courtyard" was a meeting place for numerous conversations and 
debates. In 2016, the phase for the temporary use of the space ended and the construction of an office building that lasted until summer 2017 began. Typical of the Union Street transformation process is the role played by the cyclical, temporary development of the private plot, which temporarily functioned as a public space that always varied, and was therefore interesting and eagerlyawaited. Actions, which were repeated in the same location for eight years, with a changing spatial form but maintaining the form of active planning and designing; resulted in a permanent transformation of the image of the "place," and therefore the goal of renewal was achieved. Temporality, in this case, becomes a catalyst for lasting changes, particularly in the neighborhood and the environment. The model for the entire process is shown in figure $2 .^{3}$

\section{Westergasfabriek - Amsterdam}

Primarily the Westergasfabriek area functioned as an urban gas plant. It ceased being used as a gas plant in 1992, and during the years 1996 to 2003 it underwent a process of revitalization and is now a city park with an area of 14 ha As a result, the area has become one of the most lively and recognizable places in Amsterdam. The continued attractiveness and success of the revitalization has been achieved thanks to the use of a dynamic form of planning, which has been focused on a continuous, long-term development process with no specific target form or function for the area. The immediate revival of the space enabled the introduction of temporary land use, which determined the direction of further transformations. The historic gasworks' facilities were rented out temporarily and the area was the site of numerous cultural events. The parallel processes of the renovation of the buildings and the re-naturalization of the area were carried out: new vegetation was planted, and the area was cleaned up. After later infrastructural processes there was no need to introduce a new function - the area already perfectly fitted into the functional structure of the city. The temporary use of space provided the opportunity to adapt the infrastructure to existing activities rather than adapt the activity to the proposed infrastructure. As in other cases, cooperation with the local community, in particular with artistic associations and nongovernmental organizations, and the wide involvement of social participation proved to be remarkably important. The residents of Amsterdam were constantly consulted via discussion evenings and presentations concerning the vision for the area and its permanent development, and was matched to their needs and ideas. The network of connections consisting of numerous stakeholders from the area made it possible for the area to become financial independent over time. At the beginning, the project was co-financed by the local government sector, particularly in terms of the maintenance of public places and the park; and through a business partner that guaranteed the renovation of the facilities and their temporary shared use. Later, a foundation was established for the area, in which cultural events were funded from commercial events, thanks to which the process of activating the area could be permanent. The model for entire process is shown in figure $3 .^{4}$

\section{Discussion}

Against the background of numerous effective implementations of temporary use, as well as theories, history and typology, and the possibility of using this type of space management; the presented research indicates the broad

${ }^{3}$ The case study was mainly based on press reports on websites concerning each project separately. Interesting articles about the projects include: Curating Cities: A Database of Eco Public Art 2012; Wayward 2010.

${ }^{4}$ The case study was mainly based on the following websites: Landezine 2015 ; Westergasfabriek 2018 and others. You can find out about current events at: https:// whatsupwithamsterdam.com/westergasfabriek/ accessed 01/06/2018.

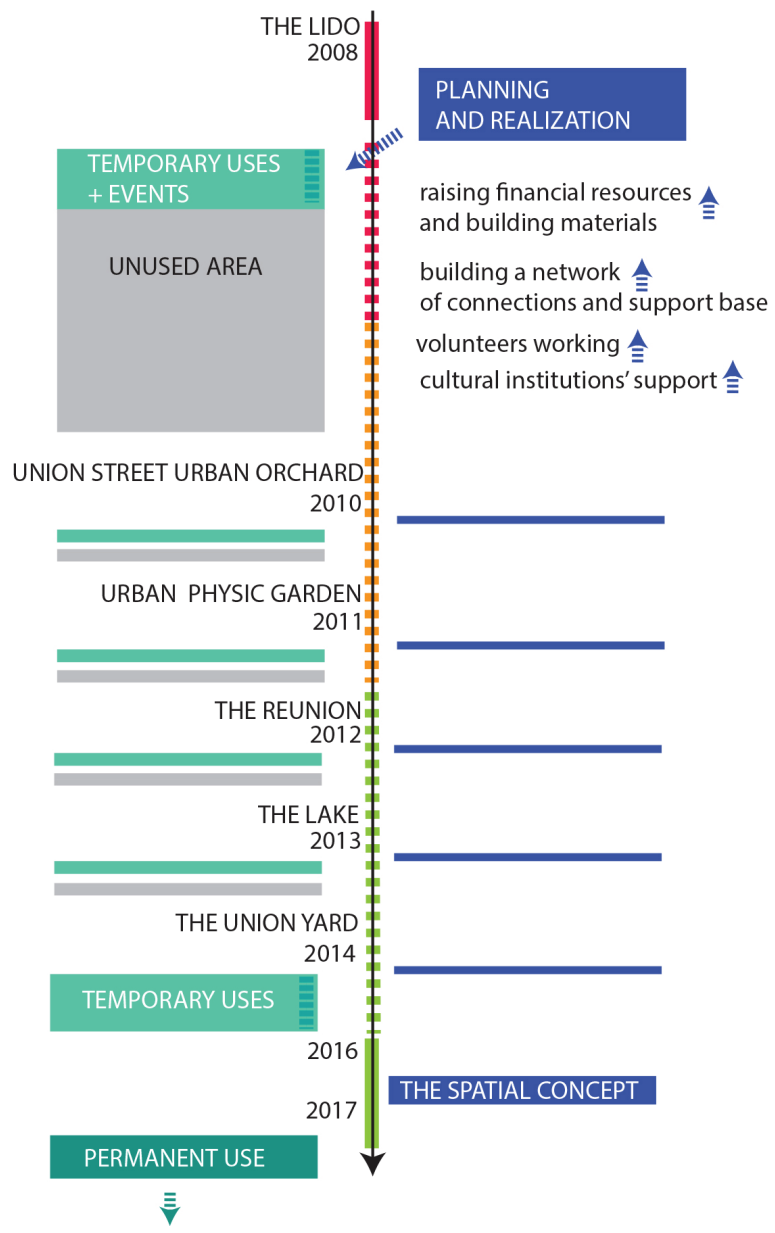

Figure 2: This model shows the elements for the entire renewal process for 100 Union Street in London.

Source: The scheme for purposes of the publication made by Karolina Szaton.

context for the intentional utilization of temporary use as a tool for urban transformation. The presented studies show the relationships between the co-occurring elements of the design process, and also show the overall process for multidimensional spatial transformations. The models for the applied solutions, in the context of particular conditions, have great potential for practical applications in other areas. This fact is particularly important when activity by urban movements significantly overtakes scientific research in the field of temporary use in areas of Polish cities. The increase in public interest in urban issues is also important. Activation, which is the domain of temporary use, releases a lot of societal emotion as well as interest, and this social movement in space is worth combining with the goals that communes have to complete. Non-governmental organizations do not need to have knowledge about the development objectives of the commune, but they have the power and prime-movers who can act as the basis for broad cooperation and the development of socially initiated action. Activities in a space that are left to themselves, may or may not cause positive permanent changes. Often, however, they have the potential, which, when supported by a broader context of action, can lead to positive, lasting changes in a space that are difficult to achieve using only typical design and planning methods. The utilization of temporary use, as the examples show, provides the possibility for dynamics, 


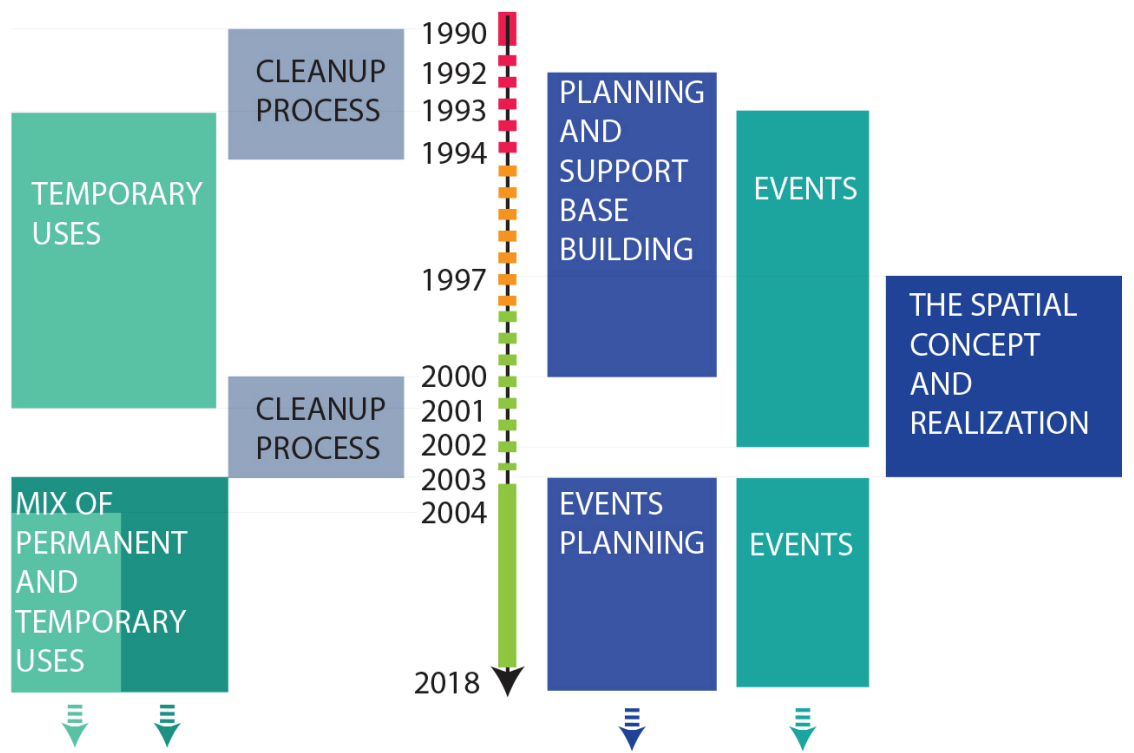

Figure 3: This model shows the elements for the entire renewal process for Westergasfabriek in Amsterdam. Source: The scheme for purposes of the publication made by Karolina Szaton.

action, direction, and movement in the design process. There are new challenges ahead for the contemporary urbanist: "We will be bound time and again to dissolve existing formalizations and formalize informal practices and integrate them into established structures" (Oswalt et al. 2013, p. 6.).

\section{Summary}

The topic of temporary use as an element of the strategy and processes of space transformation may impose a deceptively logical contradiction. First of all, the genesis of temporary use is from the bottom-up: spontaneous activities appearing in urban space in response to the current needs of society. Can these activities be made planned activities?

Secondly, they are, by definition, actions that can end unpredictably; so the following question arises: how is it possible to plan the "unplanned"?

The answer to the first question is a number of existing processes that are planned using elements of temporary use that are represented by the cases studied above. "Instead of approaching, as a problem, it is now a pivotal component of new development strategies" (Oswalt et al. 2013). What causes temporary use to have the potential to contribute to lasting transformations and transformations of urban space? The investigated cases show that temporary use of space can occur both as the only form of an area's development (a process of recurring projects), or as a process consisting of a combination of permanent and temporary developments. Different types of development may occur together or occur interchangeably depending on the specific objectives that they have to meet in the context of the overall transformation process. Therefore, the utilization of temporary use as part of the process is the answer to the second question: how to use temporary space management as an effective tool. The key to understanding the role of temporary use in a planned renovation of an area is in the fact that the permanent development is not always the determinant of the effective action. The infrastructure project is often implemented only when the space has been freed from years of growing problems, or only when it appears on the "mental map" of the community. Permanent development is often the culmination of changes, not the main purpose of temporary development. It is worth appreciating the potential, and using temporary use as a tool for modern space renewal, because, as Sławomir Gzel claims: "Temporary use ... is a new qualitative change in the way of thinking about the city - a new logic is born, the rules of the game are changed" (Gzell 2015).

\section{References}

Architecture \& Design Scotland 2018, Stalled Spaces Scotland. Available from: <https://www.ads.org.uk/stalled-spacesscotland/>. [1 June 2018].

Bauman, Z 2000, Liquid Modernity, Polity Press, Cambridge.

Beekmans, J \& DeBoer, J 2014, Pop-Up City, BIS Publishers, Amsterdam.

Bishop, P \& Williams, L 2012, The temporary city, Routledge, Abingdon.

Curating Cities: A Database of Eco Public Art 2012, Southwark Lido. Available from: <http://eco-publicart.org/southwarklido/>. [1 June 2018].
Florida, R 2010, The birth of the creative class, National Publishing House Cultural Center, Warsaw.

Fulton Area Businesses 2018. Available from: <http://faballiance. org/news/putnam-construction-starts>. [01 June 2018].

Gzell, S 2015, Wykłady o współczesnej urbanistyce, ['Lectures on contemporary town planning'] Oficyna Wydawnicza Politechniki Warszawskiej, Warszawa.

Landezine 2015, Westergasfabriek Park. Available from: <http:// www.landezine.com/index.php/2015/01/westergasfabriekpark-by-gustafson-porter/>. [1 June 2018]. 
Lydon, M \& Garcia, A 2015, Tactical Urbanism, Island Press, Washington.

NYC 2015, Putnam Triangle Plaza, Brooklyn CB2 Transportation Committee, March, 2015. Available from: <http://www.nyc. gov/html/dot/downloads/pdf/2015-03-putnam-plaza-cb2. pdf>. [1 June 2018].

OMA, Koolhaas, R \& Mau, B 1995, S,M,L,XL, The Monacelli Press, New York.

Oswalt, P, Overmeyer, K \& Misselwitz, P 2013, Urban Catalyst. The Power of Temporary Use, DOM Publishers, Berlin.

Public Space 2013, The Fight for Putman Triangle. Available from: <http://www.publicspace.org/en/post/the-fight-forputnam-triangle>. [1 June 2018].

Rosa, ML \& Weiland, UE (eds) 2013, Handmade Urbanism, Jovis Verlag $\mathrm{GmbH}$, Berlin.

What's up with Amsterdam 2018, Westergasfabriek. Available from: <https://whatsupwithamsterdam.com/ westergasfabriek/>. [1 June 2018].

Wayward 2010, Union Street Urban Orchard. Available from: <http://www.wayward.co.uk/project/union-street-urbanorchard>. [1 June 2018].

Westergasfabriek 2018, What's on. Available from: <http: //www. westergasfabriek.nl /en/whats-on/>. [1 June 2018].

Wiśniewska, W 2012, Krajobraz miejski - odnowa i kreacja w procesie odnowy, ['Urban landscape - renovation and creation in the process of renewal'], Wyd. Politechniki Łódzkiej, Łódź. 